\title{
Corporate Entrepreneurship in Pharma R\&D Organizational Transformations
}

\author{
Murta Dibirov \\ GLG, Switzerland
}

\begin{abstract}
This multiple-case study examined factors that could contribute to a richer understanding of top managers' perceptions on maintaining high-performance teams in Pharma R\&D. In addition, this multiple-case study investigated top managers' perceptions of building opportunity-based entrepreneurial culture in organizations during strategic change, considered as a critical factor for organizations during change, the results of which can be used to guide management in preventing destructive actions of business non-loyalty. Following, this multiple-case study examined the management of change within the corporate entrepreneurship literature as a means of helping organizations improve practical intelligence of defining growth goals and new enterprise growth management processes and procedures, including those relevant to change, the way they function, and formal and informal rules protecting adequacy of governance arrangements as well as the organizational culture. Participant responses to the interview question regarding capability to maintain high-performing teams resulted in themes regarding role of leadership in risk management approach, leadership development challenges, trust and commitment in inter-firm relationships, as being the top managers' perceptions and the attitudes in outsourcing R\&D industry sector since the enactment of the strategic change.
\end{abstract}

Keywords: corporate entrepreneurship, organizational change, high-performing teams, top management perceptions

\section{Introduction}

As stated by World Health Organization (WHO, 2010), the crisis in multicultural management (MCM) policies highlights the need for the use of culture and language to improve standards of care in health services organizations. Global pharmaceutical industry is forced to balance competing economic and scientific priorities before the start of research and development $(R \& D)$ of new products and services in a climate that is becoming more stressed by increased regulatory standards, high and inflexible cost structures, depleting product pipeline and increased complexities of clinical trials (Kaitin, 2010). Reduction in R\&D productivity makes only one in 13 compounds to reach the market (Khanna, 2012). Mergers and acquisitions, outsourcing, combined with downsizing and strategic alliances, have become the new norm (Lowman, Trott, Hoecht, \& Sellam, 2012). Past research has highlighted the impact that organizational transformation can have on Pharma R\&D strategic partnerships, particularly with regard to corporate entrepreneurship, governance effectiveness and maintaining high-performance teams (Dauber, Fink, \& Yolles, 2012; Strebel, 2003).

Murta Dibirov, Council Member, GLG. Email: murta.dibirov@gmail.com. 
The purpose of this qualitative study is to explore the perceptions of contract research organizations (CROs) industry sector leaders on how CROs can maintain high-performing teams in successful central laboratory services. A multiple-case study research design (Yin, 2013) was used to satisfy the goal of this exploratory research, and data have been collected through multiple sources, including in-depth individual interviews, field notes (George, 1990), and subject matter expert (SME) review and reflection of the data collected. The researcher conducted eight in-depth, face-to-face interviews with business executives holding leadership positions within the pharmaceutical industry in Europe and the US with specific knowledge on building Pharma-CROs partnerships. Additionally, SME examination on the subject matter provided formative evaluation of the interview guide/instrument and SME reflection on the data collected provided an unbiased and objective view in the analysis phase (Rowley, 2002). Triangulation of data sources was conducted to establish credibility of the researcher's reflections on the phenomena under study (Creswell, Hanson, Clark Plano, \& Morales, 2007).

\section{Materials and Methods}

To address the purpose of this study, the researcher first identified business executives holding global leadership positions within the CRO industry. The participants had suitable knowledge on the subject of the pharmaceutical industry outsourcing R\&D projects and the researcher conducted eight in-depth interviews with the subjects. An initial field test was conducted to confirm the applicability and dependability of the interview questions and data collection techniques. A semi-structured interview format provides adaptability, a feature important for case studies, in that each participant's experience is unique and therefore, questions may need to be refined (Stake, 2013). Open-ended questions, as commonly used in a semi-structured interview, identify themes and nuances in the participants' answers (Yin, 2013). An initial field test was conducted to confirm the applicability and dependability of the interview questions and data collection techniques. Purposive and snowball sampling, the most common sampling strategies in qualitative research, were applied for subject recruitment to the study. Applying this sampling strategy also reassured successful recruitment of "hidden populations"; that is, participants within the pharmaceutical industry that were not easily accessible through other sampling strategies (Noor, 2008).

\section{Results}

Different themes emerged from research results that align with the central research question of this study regarding how a corporate entrepreneurship framework can be used to explore perceptions of R\&D laboratories/CRO industry sector leaders on how CROs can maintain high-performing teams for developing successful central laboratory services. Participant responses resulted in themes regarding the role of leadership in risk management approach, leadership development challenges, trust and commitment in inter-firm relationships, as being the top managers' perceptions and the attitudes in outsourcing $R \& D$ industry sector since the enactment of the strategic change. For example, results suggested that top managers expect maintenance of high-performing teams through leadership development, trust and commitment from the organization in times of strategic changes (Hansson \& Jansson, 2013; Won \& Hannon, 2013; Wright, 2010). In addition, research results showed that top managers who perceive that when management commits to personal development of their subordinates, then career development path within the organization can be maintained by employees together with management to successfully implement the change (Saari, 2004; Simons, 2013). 


\section{Role of Leadership in Risk Management Approach}

All study participants believed that the role of top management is very critical in an organization that is undergoing a strategic change, and that top management must provide a communication strategy to share information with employees, supporting that in order for change to be sustained, management must try to maintain high-performing teams and manage risks related to building and keeping them in order to build trust and commitment in relationships with their client base.

Leadership development challenges. All research participants confirmed that when management commits to personal development of their subordinates, then career development path within the organization can be maintained with employees. Effective communication is a fundamental factor in building succession planning of managers, and contributes to the creation of an entrepreneurial environment motivating employees to work even harder and be more productive, even in times of change. In case of strategic partnerships with client management of partnering companies should work together to develop some kind of entrepreneurial ideas pool to communicate the plan of change as well as offer methods of monitoring as to how these ideas and experiences of change are internalized throughout the organization. Further findings suggested that lack of management's commitment to personal development of their subordinates, career development path within the organization affects the quality of relationships, and that management should make good-faith efforts and behave with honesty in relation to their high-performing teams.

\section{Trust and Commitment in Inter-Firm Relationships}

Half of participants believed that top managers of their strategic partners get together rarely discussing mainly technical and organizational capabilities involved in agreed relationships. These findings indicated that when top managers of both strategic partners get together to discuss skill sets of their personnel, technical and organizational capabilities involved in agreed relationships, they can focus on positive aspects regarding their reactions to organizational change and be more enthusiastic in promoting positive working relationships. Study findings are consistent with international applications of corporate entrepreneurship theory, which is an important factor that can promote successful business practices, within and between organizations (Mainela, Puhakka, \& Servais, 2014). When individuals are interactively involved in international business opportunity building, action and knowledge of personnel can mutually reinforce each other (Dunlap, Marion, \& Friar, 2014), as is also suggested in this study's findings.

Research findings provided insights supported by the extant literature and that can be used to address entrepreneurial collaborative solutions in interactions with clients to adapt to changing research environment (Lustig \& Thompson, 2013; Ullman \& Boutellier, 2008). Findings further indicated that the role of management is very critical in an organization that is undergoing change in effective communication culture and adequate sharing of information with the client base; by encouraging the breadth of services they are supporting clients with, and that influences organizational strategy and our operating plan (Kaitin, 2010; Sams-Dodd, 2013). Three distinct elements make up entrepreneurial culture and are associated with how managers build their CRO/R\&D laboratory's positioning in the industry and the expectations for changes that need to be implemented as well as how they treat their current clients (Mirowski \& Van Horn, 2005). All research participants underlined the role of top managers in risk management and current challenges in leadership development within the organization. Half of study participants mentioned trust and commitment culture in inter-firm relationships skills as crucial for maintaining high-performing teams. Accordingly, research findings suggested that managers could help avert 
negative behaviors on the part of clients when they balance and implement strategies and operating tactics, while preserving the current business delivery. As a result, clients are willing to work together with management to implement the change (Chow \& Chang, 2011; Coates \& Bals, 2013).

\section{Discussion}

Building higher performing teams in comparison to their present teams was perceived by top managers as of critical importance in relation to risk management approach during the implementation of change (Hansson \& Jansson, 2013; Won \& Hannon, 2013; Wright, 2010). This element of corporate entrepreneurship was considered by Saari (2004) and Simons (2013) as to be tied to management commitment to personal development of their subordinates to ensure that employees together with management successfully implement the change. Accordingly, research findings suggested that trust and commitment culture in inter-firm relationships could help overcome conservatism of the part of clients when R\&D lab recognizes the role of global alliance management increasing the governance, of skilled professionals in its leadership teams that are trying to manage alliances with different companies. The significance of opportunity-based view of entrepreneurship through application of practical intelligence and communication was found to be another support factor in strategic relationships with clients during times of uncertainty and ambiguity (Baum, Bird, \& Singh, 2011; Brown, Davidsson, \& Wiklund, 2001; Stevenson \& Jarillo, 1990).

Effectiveness of MCM strategies for influencing policies in organizational settings is a subject of multiple researches. Ronen and Kraut (1977) were the first, who in scholar literature clustered countries based on employee work values and attitudes. Geert Hofstede in 80s introduced for different geographic regions four dimensions of power distance, uncertainty avoidance, individualism vs. collectivism, and masculinity vs. femininity as the key elements of MCM. Fons Trompenaars proposed model of national culture differences as a framework for cross-cultural communication applied to general business and management, and added layers in MCM: universalism vs. particularism, individualism vs. collectivism (communitarianism), neutral vs. emotional, specific vs. diffuse, achievement vs. ascription, internal vs. external control, and sequential vs. synchronic (Trompenaars \& Hampden-Turner, 1997).

A critic of above theories claims their inadequacy to popularity and little value to those organizations promoting economic growth. Frey (1984) suggested that future theory and research should concentrate on the interaction between economic growth by emphasizing factors at individual, national, and international levels. Schäffner, Gebert, Schöler, and Kirch (2006) found that the firm’s culture should incorporate the normative assumption or belief that diversity is an opportunity and becomes a predictor of team innovativeness. Kearney and Gebert (2006) confirmed that diversity in age, nationality, and functional background have a positive effect on team innovativeness in a high transformational leadership context, but no effect in a low one. A curvilinear relationship between diversity and performance was identified by Richard, Barnett, Dwyer, and Chadwick (2004). Kochan, Bezrukova, Ely, Jackson, Joshi, Jehn, Leonard, Levine, and Thomas (2003) found few positive or negative direct effects of diversity on performance.

Scholars of corporate entrepreneurship contend that change management constitutes a natural component of the working lives of organizations (Brown et al., 2001; Simons, 2013; Stevenson \& Jarillo, 1990). A corporate entrepreneurship framework offers a means for better understanding, within the context of strategic change (Stevenson, 1983), managers' perceptions of maintaining high-performance teams in an organization (Baum et al., 2011; Lustig \& Thompson, 2013; Ullman \& Boutellier, 2008). Given that strategic change is an 
inevitable factor in the life cycle of modern organizations, the findings from this study contribute to a better understanding of how change in organizations can be successfully and more effectively implemented (Kaitin, 2010; Mirowski \& Van Horn, 2005). Overall literature research claims that high-performing teams maintenance needs to be properly managed if any business benefits are to be reaped. If properly managed, diversity likely will respond to these business goals. This does not preclude that diversity at all levels of society should be a goal "per se". Beyond business benefits, research should pay more attention to societal benefits attached to the promotion of more inclusive and diverse workforces.

\section{Shift from Multiculturalism to Diversity as a Tool in Growing Organizations}

Rosado (1996) proposed a new definition of multiculturalism as a system of beliefs and behaviors that recognizes and respects the presence of all diverse groups in an organization or society, acknowledges and values their socio-cultural differences, and encourages and enables their continued contribution within an inclusive cultural context which empowers all within the organization or society (p. 2).

Cox (2010) proclaimed diversity management as a more dynamic approach and away to get from a heterogeneous work force the same productivity, commitment, quality, and profit as from the homogenous one. Harper (2011) paid special attention to practical application aspect of MCM policies and their variations across countries. The author emphasized the respect to the various cultures in an organization, their embedding in the policies, and promoted the cultural diversity. Cotter (2011) reinforced the importance of MCM policy frameworks. The author described "Interculturalism" as a concept with focus on interaction and communication between different cultures. Interactions of cultures provide opportunities for the cultural differences to communicate and interact to create multiculturalism. The author used another concept of "Cultural Isolation", presenting any specific ethnic, religious, or cultural community values as a central, key management subject that should center policy frameworks on diversity and cultural uniqueness.

Harper (2011) defined "Interculturalism” and "Cultural Isolation” as a borderline between several business leadership MCM styles: controlling vs. adapting, and prospecting vs. defending. Multicultural management became an education discipline that facilitates providing accurate cultural information, leading to a productive psychosocial orientation to an effective cross-cultural communication. Agency for Healthcare Research and Quality (2013) defined national cultural health as focused on sufficient values, interests, and principles of the nation, a person or group lives in. Ethnic cultural health is focused on cultural values, interests, and principles of the ethnic group a person belongs to or interacts with.

Dawkins (2006) suggested the explanation of developing ethnocentrism by genetic The Selfish Gene, while Hammond and Axelrod (2006) have attempted to select the ethnocentric phenotypes. De Dreu, Greer, Van Kleef, Shalvi, and Handgraaf (2011) evaluated the correlation between ethnocentrism and oxytocin hormone levels in blood. They found that in randomized controlled trials oxytocin creates intergroup bias because oxytocin motivates in-group favoritism and, to a lesser extent, out-group derogation. Goleman (2013) defined the links between oxytocin releases with activation of amygdala, the brain radar of danger. McCleskey (2006) described this three-phase physiologic process. The release of stress hormones leads to excessive death of neurons in the critical pathways responsible for emotional regulation: emotion defeats reason. Once an association is made through repetition of a behavior, it increases the likelihood one will continue to make the same association and decreases the likelihood of a different association. Behavior change involves both unlearning and relearning and developing new chemical connections in the brain; this explains the reason why "wired" patterns of behavior are so difficult and slow to change. 


\section{From Anti-MCM to Organizational Change Resistance}

Cultural models are made up of culturally derived ideas and practices that are embodied, enacted, or instituted in everyday life (Fryberg \& Markus, 2007). Dauber et al. (2012) suggested performance assessment (i.e., inward-oriented operations) as a mechanism of strategic changes in organizational structure. The authors consider learning processes, such as "single-loop learning" that refers to the detection of errors and the adjustment of strategies to overcome mistakes. Double-loop learning, however, questions existing underlying assumptions, that is, organizational culture, and may lead to more fundamental changes in strategies and their operationalization. Dauber's concept of organizational culture model transformation into a more holistic, comprehensive, and interdisciplinary cultural dynamics in organizations can serve as a meaningful reference to build new cultures.

Relevance of cultural models to business, their impact on critical variations as cultural shock, negotiation failures, strategic collaboration failure, as well as cultural routine business prototypes (centralized vs. decentralized decision-making, risk management, engagement, rewards and organizational loyalty) define future of companies, their strategic partnerships, competitiveness, sustainability, and innovativeness. To reach the new level of performance, the organization has to empower self-organizing teams and transform the role of the manager from controller to enabler.

Beer, Eisenstat, and Spector (1990) proposed six steps of effective change: (1) mobilize commitment to change through joint diagnosis of business problems; (2) develop a shared vision of how to organize and manage for competitiveness; (3) foster consensus for the new vision, competence to enact it, and cohesion to move it along; (4) spread revitalization to all departments without pushing it from the top; (5) institutionalize revitalization through formal policies, systems, and structures; and (6) monitor and adjust strategies in response to problems in the revitalization process.

\section{Conclusion}

Scholars of corporate entrepreneurship contend that organizational change constitutes a natural component of the working lives of organizations (Brown et al., 2001; Simons, 2013; Stevenson \& Jarillo, 1990). A corporate entrepreneurship framework offers a means for better understanding, within the context of strategic change (Stevenson, 1983), managers' perceptions of technical and organizational maturity, efficient governance, and maintaining high-performance teams in an organization (Baum et al., 2011; Lustig \& Thompson, 2013; Ullman \& Boutellier, 2008). Given that strategic change is an inevitable factor in the life cycle of modern organizations, the findings from this study contribute to a better understanding of how change in organizations can be successfully and more effectively implemented, as well as how to forecast allocation of resources so as to bring about the desired change (Kaitin, 2010; Mirowski \& Van Horn, 2005).

This multiple-case study examined factors that could contribute to a richer understanding of top managers' perceptions on maintaining high-performance teams. It also sought to advance knowledge that could help organizational leadership recognize the significance of establishing mutual trust and networking structures with their clients so they may successfully cooperate with their strategic partners during times of strategic change. In addition, this multiple-case study investigated top managers' perceptions of building opportunity-based entrepreneurial culture organizations during strategic change, considered as a critical factor for organizations during change, the results of which can be used to guide management in preventing destructive actions of business non-loyalty. Following, this multiple-case study examined the management of change within the 
corporate entrepreneurship literature as a means of helping organizations improve practical intelligence of defining growth goals and new enterprise growth management processes and procedures, including those relevant to change, the way they function, and formal and informal rules protecting adequacy of governance arrangements as well as the organizational culture. Participant responses to the interview question regarding capability to maintain high-performing teams resulted in themes regarding the role of leadership in risk management approach, leadership development challenges, trust and commitment in inter-firm relationships, as being the top managers’ perceptions and the attitudes in outsourcing R\&D industry sector since the enactment of the strategic change.

\section{References}

Agency for Healthcare Research and Quality. (2013). Revamped processes and systems enhance access to high-quality interpretation services for patients with limited English proficiency. Retrieved from http://www.innovations.ahrq.gov/content.aspx?id=2657

Baum, J. R., Bird, B. J., \& Singh, S. (2011). The practical intelligence of entrepreneurs: Antecedents and a link with new venture growth. Personnel Psychology, 64(2), 397-425.

Beer, M., Eisenstat, R. A., \& Spector, B. (1990). Why change programs don’t produce change. Harvard Business Review, 68(6), 158-166.

Brown, T. E., Davidsson, P., \& Wiklund, J. (2001). An operationalization of Stevenson’s conceptualization of entrepreneurship as opportunity-based firm behavior. Strategic Management Journal, 22(10), 953-968.

Chow, S. C., \& Chang, M. (2011). Adaptive design methods in clinical trials. Boca Raton, FL: CRC Press.

Coates, M., \& Bals, L. (2013). External innovation implementation determinants and performance measurement: A case study from the pharmaceutical industry. Technology and Investment, 4(2), 131-143.

Cotter, A. M. M. (2011). Culture clash: An international legal perspective on ethnic discrimination. Ashgate Publishing, Ltd..

Cox, T. (2010). Cultural diversity in organizations: Theory, research and practice. San Francisco: Berrett-Koehler Publishers, Inc..

Creswell, J. W., Hanson, W. E., Clark Plano, V. L., \& Morales, A. (2007). Qualitative research designs: Selection and implementation. The Counseling Psychologist, 35(2), 236-264.

Dauber, D., Fink, G., \& Yolles, M. (2012). A configuration model of organizational culture. SAGE Open. Retrieved from http://sgo.sagepub.com/content/2/1/2158244012441482.full-text.pdf+html

Dawkins, R. (2006). The selfish gene. Oxford University Press.

De Dreu, C. K. W., Greer, L. L., Van Kleef, G. A., Shalvi, S., \& Handgraaf, M. J. J. (2011). Oxytocin promotes human ethnocentrism. Proceedings of the National Academy of Sciences of the United States of America. Retrieved from http://www.pnas.org/content/early/2011/01/06/1015316108

Dunlap, D., Marion, T., \& Friar, J. (2014). The role of cross-national knowledge on organizational ambidexterity: A case of the global pharmaceutical industry. Management Learning, 45(4), 458-476. doi: 10.1177/1350507613480099

Frey, R. S. (1984). Need for achievement, entrepreneurship, and economic growth: A critique of the McClelland thesis. The Social Science Journal, 21(2), 125-134.

Fryberg, S. A., \& Markus, H. R. (2007). Cultural models of education in American Indian, Asian American and European American contexts. Social Psychology of Education, 10(2), 213-246.

George, J. M. (1990). Personality, affect, and behavior in groups. Journal of Applied Psychology, 75(2), 107-116.

Goleman, D. (2013). Focus: The hidden driver of excellence. London: Bloomsbury Publishing.

Hammond, R. A., \& Axelrod, R. (2006). The evolution of ethnocentrism. Journal of Conflict Resolution, 50(6), 926-936.

Hansson, A., \& Jansson, A. (2013). Exploring trust and commitment in inter-firm relationships when outsourcing R\&D: A qualitative study of pharmaceutical firms and clinical research organizations (Master thesis, Department of Business Studies, Uppsala University).

Harper, T. L. (2011). Dialogues in urban and regional planning. London: Routledge.

Kaitin, K. I. (2010). Deconstructing the drug development process: The new face of innovation. Clinical Pharmacology \& Therapeutics, 87(3), 356-361. doi: 10.1038/clpt.2009.293 
Kearney, E., \& Gebert, D. (2006). Does more diversity lead to more innovativeness? An examination of the critical role of leadership. IFSAM VIIIth World Congress, Track 16, Berlin, September 28-30.

Khanna, I. (2012). Drug discovery in pharmaceutical industry: Productivity challenges and trends. Drug Discovery Today, 17(19/20), 1088-1102.

Kochan, T., Bezrukova, K., Ely, R., Jackson, S., Joshi, A., Jehn, K., Leonard, J., Levine, D., \& Thomas, D. (2003). The effects of diversity on business performance: Report of the diversity research network. Human Resource Management, 42(1), 3-21.

Lowman, M., Trott, P., Hoecht, A., \& Sellam, Z. (2012). Innovation risks of outsourcing in pharmaceutical new product development. Technovation, 32, 99-109. doi: 10.1016/j.technovation.2011.11.004

Lustig, K. D., \& Thompson, M. L. (2013). Strategic outsourcing of pharmaceutical R\&D: Bringing pharma and drug discovery into the information age. Chimica Oggi-Chemistry Today, 31(4), 14-17.

Mainela, T., Puhakka, V., \& Servais, P. (2014). The concept of international opportunity in international entrepreneurship: A review and a research agenda. International Journal of Management Reviews, 16(1), 105-129. doi: 10.1111/ijmr.12011

McCleskey, K. (2006). Neuro-affective therapy. Atlanta, GA: Karen McCleskey Workshop.

Mirowski, P., \& Van Horn, R. (2005). The contract research organization and the commercialization of scientific research. Social Studies of Science, 35(4), 503-548

Noor, K. B. N. (2008). Case study: A strategic research methodology. American Journal of Applied Sciences, 5(11), $1602-1604$.

Richard, O. C., Barnett, T., Dwyer, S., \& Chadwick, K. (2004). Cultural diversity in management, firm performance, and the moderating role of entrepreneurial orientation dimensions. Academy of Management Journal, 47(2), 255-266.

Ronen, S., \& Kraut, A. I. (1977). Similarities among countries based on employee work values and attitudes. Columbia Journal of World Business, 12(2), 89-96.

Rosado, C. (1996). Toward a definition of multiculturalism. Retrieved from https://www.academia.edu/777187/Toward_a_Definition_of_Multiculturalism

Rowley, J. (2002). Using case studies in research. Management Research News, 25(1), 16-27.

Saari, H. L. (2004). Risk management in drug development projects. Helsinki University of Technology, Laboratory of Industrial Management, Report 2004/1. Monikko Oy: Espoo.

Sams-Dodd, F. (2013). Is poor research the cause of the declining productivity of the pharmaceutical industry? An industry in need of a paradigm shift. Drug Discovery Today, 18(5-6), 211-217.

Schäffner, M., Gebert, D., Schöler, N., \& Kirch, J. (2006). Diversity, its risk and chances for team innovativeness. IFSAM VIIIth World Congress, Track 16, Berlin, September 28-30.

Simons, R. (2013). The entrepreneurial gap: How managers adjust span of accountability and span of control to implement business strategy. Harvard Business School Accounting \& Management Unit Working Paper No. 13-100. Retrieved from http://ssrn.com/abstract=2280355 or http://dx.doi.org/10.2139/ssrn.2280355

Stake, R. E. (2013). Multiple case study analysis. New York, NY: Guilford Press.

Stevenson, H. H. (1983). A perspective on entrepreneurship. Harvard Business School.

Stevenson, H. H., \& Jarillo, J. C. (1990). A paradigm of entrepreneurship: Entrepreneurial management. Strategic Management Journal, 11, 17-27.

Strebel, P. (2003). Trajectory management: Leading a business over time. England, Chichester: John Wiley \& Sons, Ltd..

Trompenaars, F., \& Hampden-Turner, C. (1997). Riding the waves of culture. New York, NY: McGraw-Hill.

Ullman, F., \& Boutellier, R. (2008). A case study of lean drug discovery: From project driven research to innovation studios and process factories. Drug Discovery Today, 13(11/12), 543-550. doi: 10.1016/j.drudis.2008.03.011

Won, J. C., \& Hannon, D. J. (2013). Influence of resource allocation on teamwork and team performance within self-organizing teams. Proceedings of the Human Factors and Ergonomics Society Annual Meeting, 57(1), 270-274. doi: $10.1177 / 1541931213571060$

World Health Organization [WHO]. (2010). How health systems can address health inequities linked to migration and ethnicity. Copenhagen, WHO Regional Office for Europe.

Yin, R. K. (2013). Case study research: Design and methods. Thousand Oaks, CA: Sage Publishing. 